\title{
Survey on Driverless Train Operation for Urban Rail Transit Systems
}

\author{
Yihui Wang ${ }^{1} \cdot$ Miao Zhang ${ }^{1} \cdot$ Jiaqi $^{M^{2}} \cdot$ Xuesong Zhou $^{3}$
}

Received: 12 July 2016/Revised: 30 November 2016/Accepted: 4 December 2016/Published online: 18 December 2016

(c) The Author(s) 2016. This article is published with open access at Springerlink.com

\begin{abstract}
The length of metro lines with driverless train operation (DTO) systems is increasing globally and is predicted to triple in the next 10 years. This paper gives the history and future trend of the DTO systems. The opportunities provided by the DTO systems, such as lower operation costs, increased capacity, and energy efficiency, are explained and the relevant research are reviewed. Furthermore, the challenges faced by the DTO systems are analyzed, such as safety issues, train control technology, and emergency situations.
\end{abstract}

Keywords Driverless train operation - Urban rail transit . Energy efficiency $\cdot$ Safety $\cdot$ Capacity

\section{Introduction}

Technical developments in the last century have made the operation of driverless train operation (DTO) possible. For urban rail transit systems, there is a growing trend to employ DTO globally. As reported in the annual world report of metro automation [1], in 2013, there are $674 \mathrm{~km}$

Yihui Wang

yihui.wang@bjtu.edu.cn

1 State Key Laboratory of Rail Traffic Control and Safety, Beijing Jiaotong University, Beijing 100044, People's Republic of China

2 Transportation Solutions and Technology Applications Division, Leidos, Inc., Reston, VA 20190, USA

3 School of Sustainable Engineering and the Built Environment, Arizona State University, Tempe, AZ 85287, USA

Editor: Baoming Han of automated metro in operation consisting of 48 lines in 32 cities, where 40 and $32 \%$ of the automated lines are concentrated in Asia and Europe, respectively. In addition, the report stated that the observatory data for new DTO projects highlight a trend for exponential growth in metro automation and the kilometers of fully automated lines is expected to reach over $1800 \mathrm{~km}$ by 2025 [1].

According to the International Electro-Technical Commission (IEC) standard IEC 62290-1 [2], there is a clear classification of the grade of automation (GoA) for urban rail transit systems as shown in Fig. 1:

1. GoA 1: Non-automated train operation (NTO)

There is a driver in the cabin, who is responsible for driving trains based on wayside or cabin signal, opening and closing door, observing the guideway, and stopping trains in case of emergency. In addition, automatic train protection (ATP) system prevents unsafe movements of trains in respect of the signals and the train speed.

2. GoA 2: Semi-automated train operation (STO)

Automatic train operation (ATO) system controls the train movement by the acceleration and deceleration commands. The movement of the train is supervised by the ATP system. The driver in the cabin observes the guideway and stops the train in case of a hazardous situation. The opening and closing of doors may be done automatically or performed by the driver.

3. GoA 3: DTO

Compared with GoA 2, there is no driver in the cabin to observe the guideway and stop the train in case of a hazardous situation. There is an operation staff on board. Safe departure of the train from a station, including door closing, could be the responsibility of the operation staff or may be done automatically. 


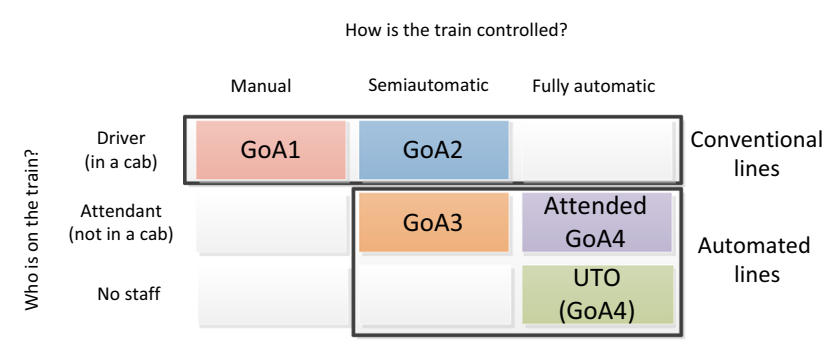

Fig. 1 Automated metro terminology [2, 3]

4. GoA 4: Unattended train operation (UTO)

Compared with GoA 3, there is no operation staff on board. So the safe departure of the train from a station, including door closing, has to be done automatically. The UTO system can detect and manage the hazardous conditions and emergency conditions by introducing guideway intrusion detection, platform and onboard CCTV, etc.

UTO is only possible for systems with GoA 4; however, in practice, not all GoA 4 systems are operated unattended. Based on the observations of automated metros, most of the GoA 4 systems are operated with attendants onboard every train [3]. So GoA 4 systems can be operated either unattended or with an attendant onboard, while the attendant in GoA 4 is not essential for the system unlike the attendant in GoA 3. In this paper, we use the DTO to involve train operation systems without traditional drivers and do not distinguish the difference between GoA 3, attended-GoA 4, and UTO.

The primary motivations for automated metro systems are faster services, economy, safety, and energy efficiency [4]. Compared with the traditional metro, the DTO system can shrink the headway to a mere $60 \mathrm{~s}$ [4]. Therefore, additional trains can be put into the system during the peak hours to transport passengers. DTO system can respond immediately to congestion, running more trains without the need for extra staff. Moreover, the frequency of the trains can also be enhanced in the low-traffic hours, as more and shorter trains can be inserted in traffic without the need for operational staff. On one side, driverless trains are being championed as a way of avoiding human error and reaching new levels of efficiency at a time when many metro systems are operating at the very limits of their capacity. On the other, critics are concerned about entrusting public safety to a driverless system, as well as the job losses.

This study gives a general overview for DTO systems. The development history and future trends for DTO systems are briefly discussed in Sect. 2. In Sect. 3, the opportunities provided by DTO systems, such as lower operation costs, increased capacity, and reliability, are explained and the relevant research is summarized. Furthermore, the challenges of DTO systems are listed in
Sect. 4, which involves safety issues, train control technology, communication systems, etc. Finally, Sect. 5 concludes the paper.

\section{Development History and Future Trends}

In public perception, DTO is a very recent development since it associated with the development of technologies and innovations. However, the first DTO lines could date back to 1960s. The first fully automated subway line is between Grand Central to New Utrecht Avenue in New York, which is implemented in 1962 [5]. The London Underground Victoria Line was opened in 1968, where trains are driven automatically, but there is a train operator onboard to supervise operations and operate the train doors [6]. The first full-scale automated metro opened Lille, France, in 1983, which is made up of two lines that serve 60 stations and runs over $45 \mathrm{~km}$ [7]. In 1985, the fully automated metro Sky-Train was introduced in Vancouver, Canada, which has three lines and 47 stations in total [8]. In 1990s, three new French automated metro systems and four new Asian automated metro systems were built and the total length of the automated lines was reached to $196 \mathrm{~km}$ [1]. In particular, automated metro Line 14 of Paris opened in 1998 to commemorate the 100th anniversary of Paris metro [9]. By 2016, there are $789 \mathrm{~km}$ of automated metro in operation consisting of 53 lines and 822 stations in 36 cities, where $50 \%$ concentrated in four countries including France, Korea, Singapore, and the United Arab Emirates. Among these countries, France ranks first in terms of the length of metro lines with DTO system, and the proportion is about $16 \%$ [10].

The development of metro automation has a history nearly 50 years. The process indicates that DTO provides a quite effective solution to increase security, reliability, and meet the increasing demands of transport capacity. Meanwhile, DTO can result in operational improvements so that the subway operators can provide better public services [10].

It is stated that there is an exponential growth trend in automated metro, and the growth rate for kilometers of fully automated lines is expected to triple that of the current decade, reaching over $1800 \mathrm{~km}$ by 2025 [1]. Geographically, it is noted that Europe will lead in terms of the kilometers growth by $37 \%$ during 2014 and 2025 . Asia and Middle East will consolidate their strong presence by 27 and $21 \%$, respectively. South America will continue to develop new lines with the successful experience of Sao Paulo and will take up to $10 \%$ of the worldwide growth distribution. In addition, Austria will have the first DTO system between 2014 and 2025 [1]. 


\section{Opportunities}

More and more automated metro operates with true driverless systems, where trains run automatically with no onboard staff necessary. All aspects of train operations are handled automatically or by remote technologies with the information provided by CCTV and onboard telemetry. An advanced control center monitors the operation of trains and potential hazards.

\subsection{Lower Operation Costs}

Due to the high level of automation, the initial cost of the DTO systems is much higher than the traditional metro systems as pointed out in [11]. However, the staff reductions in DTO systems could result in a much lower management and training cost, especially with the increasing cost for labor. Meanwhile, the maintenance cost is also declined for the DTO systems. The total operation costs of the DTO systems will also decrease. In a study of European mainline railways [12], staff per train kilometers is identified to be an important determinant of cost inefficiency. Andreau and Ricart [13] concluded that the availability and scheduling of train drivers is highly linked to the organizational efficiency of urban rail transit systems. So staff savings available from DTO systems are obvious. The Paris metro reported that the operation costs of DTO systems are $30 \%$ lower when compared with the conventional lines [14]. In addition, the operator of DTO systems in Keolis stated that the operational cost saving is about $10 \%$ due to staff reductions. The operational experience of Copenhagen automated metro showed that there are no labor costs associated with incremental changes in the supply of capacity and the costs are limited to the effort needed to compile and introduce the new service plan, the consequent changes to energy, and equipment wear and tear levels [15]. Furthermore, the passenger demand of metro systems increases with the increasing of train frequencies as stated in [16-18]. Hence, the ridership of DTO systems should increase if the trains are operated with half the length at twice the frequency, which may increase the traction energy cost in a certain level but without any additional driver cost. It is concluded in [3] that the strategy that operates the same total car kilometers but with shorter trains and higher frequencies for DTO systems is demand-generative, minimizing traction energy consumption while providing better performance than a longer-train, lowerfrequency solution.

\subsection{Increased Capacity and Reliability}

Capacity is increased by higher operational speeds and train frequencies provided by DTO systems, where the headway can be reduced to $75 \mathrm{~s}$, even to $60 \mathrm{~s}[19,20]$. In addition, DTO systems can reduce the turnaround times at the terminus to enable higher frequency. Therefore, additional trains can be put into the system during the peak hours to transport passengers. Moreover, DTO systems can respond immediately to congestion, running more trains without the need for extra staff. In addition, the frequency of the trains can also be enhanced in the low-traffic hours, as more and shorter trains can be inserted in traffic without the need for operational staff. Shorter headways provided by DTO systems reduce the expected waiting times of passengers. Additionally, more frequent arrivals of trains at platforms also shorten the boarding and alighting process, which results in shorter dwell times. It is stated in [7] that if the headway between trains is reduced by $42 \mathrm{~s}$, then the dwell time is about $3 \%$ less. In addition, better regularity and consistency of station stop times are also enabled by the improvements in frequency for DTO systems, while human factors can create variability and small delays in GoA 2 and GoA 3 lines [21]. The Paris Metro reported that after upgrading the traditional metro system of Line 1 to DTO system, the same level of service can be provided by fewer rolling stock units [19]. Moreover, the removal of the driver cabins enhances the physical space for passengers, which added 6\% to capacity for Paris Metro Line 1 [19].

Reliable and robust operation is significant for metro systems. As pointed in [22], DTO systems require trains to stop at any point if necessary, such as the evacuation of people in emergency circumstances and train malfunctions. It is showed that the long-term unreliability can reduce the passenger demand and metro effectiveness [23]. The increase in the level of automation enhances the reliability and robustness of urban rail transit systems. In [20], it is reported that $33 \%$ of 5 -min delay incidents could be reduced by switching from manual to automatic operation, i.e., from GoA 1 to GoA 2 or above. There are several reasons that DTO systems could improve the reliability [7, 20, 24, 25]: (1) The adjustments of running times and dwell times can be more precise and comprehensive; (2) removal of drivers reduces the opportunities for incidents caused by human error; and (3) DTO system manages the operations in terms of seconds, and it can recognize a system disruption more promptly. The Dubai Metro reported that the service availability of their DTO systems is $99.97 \%$ [26]. In addition, the DTO system operator Keolis stated that the availability of DTO systems is between 99 and $99.99 \%$. The reliability of the DTO systems is much higher than that of the traditional metro systems, the availability of which is between 96 and $98 \%$. However, Cohen et al. [3] claimed that the comparison between those sources may not be valid since a consistent measurement definition is needed and it should be validated over several years of data collection. 


\subsection{Increased Flexibility}

Flexibility is identified as the key operational advantage of DTO systems by all automated metros [3]. DTO system breaks the connection between train availability and staff availability, which means that trains can be more easily included in or removed from circulation based on the passenger demand [27, 28]. This real-time adaption of capacity to passenger demand can provide the passengers with better service and keep the operation costs as lower as possible. For sporting or other special events, in an automated line as many trains as needed can be injected into the required part of the line with short headways in response to the peaks in demand. Moreover, only a short notice, e.g., like $1 \mathrm{~h}$ before the special events, is needed rather than 3 months to schedule trains for automated metros as stated in [3]. The flexibility of DTO systems to increase capacity for passenger demand was demonstrated by the Vancouver Sky-Train during the Expo' 86 world's fair in its first year operation and during the Winter Olympics in February 2010 [29].

The flexibility of DTO systems makes variable train services possible during off-peak hours and at night to lower operational costs. DTO systems also make the 24/7 operations less constrained because the operation of trains is less dependent on staff availability. Now, the Copenhagen metro has enabled the $24 / 7$ operation [27, 30].

\subsection{Energy Efficiency}

Energy efficiency is a major goal for any railways administration both economically and environmentally. As pointed out in [31], the energy cost is an important component for the total operation cost of railway companies. So it is important to introduce the energy-efficient strategies to reduce energy consumption of trains. Energy consumption in urban rail systems is affected by many factors (such as rolling stock, lighting systems, and air-conditioning systems) and the distribution of the energy consumption for these factors [32]. As illustrated in Fig. 2, 40-50\% of the energy of urban rail transit systems is consumed by the traction of trains. The airconditioning systems contribute to $25-35 \%$ of the total energy consumption. In addition, the energy consumption of the escalator and lift systems is about $10-14 \%$ of the total energy consumption. Moreover, the lighting systems consume about $8-12 \%$ of the total energy consumption (Fig. 3).

Automatically controlled trains indeed consume less energy due to the optimized acceleration, traction, and braking processes, and it is reported that the energy consumption can be cut by as much as $30 \%$ depending on the degree of automation [33]. In the operation experience of the Vancouver Sky-Train system [34], the energy consumption per passenger-kilometer is just less than half the average of the other systems since the braking process of train could be coordinated with other accelerating trains to enhance the usage of regenerative energy in DTO systems. Since the usage of the regenerative energy is strongly affected by the power supply system and the traffic density, the Singapore MRT operator introduced inverters at substations to recover the regenerative energy for station auxiliary loads. These inverters can recover up to $5 \%$ of the total energy used by the urban rail transit systems [35].

In [36], an energy-efficient optimization approach is presented based on genetic algorithms, which reduces the energy consumption to $32.89 \%$ with a small increase (around $0.51 \%$ ) in the travel time.

Air-conditioning system is important for the passenger satisfaction. Various methods can be introduced to reduce the energy consumption, such as using equipment with better energy efficiency performance, installing carbon dioxide sensors to automatically adjust fresh air supply rates, and installing temperature sensors to make the system run when necessary [35]. It is stated in [7] that $86 \%$ of the world's DTO metro lines install the PSDs. The installation of platform screen doors (PSDs), especially the full height PSDs, can reduce the energy consumption of the airconditioning system by 50\% when compared to those without PSDs, because PSDs act as barriers to isolate the stations from the tunnels or outside area [35]. In addition, LED lighting can reduce the energy consumption of the lighting system by $30 \%$ and the LED lighting now is a common standard for automatic trains [4].

Furthermore, DTO systems could provide a flexible way to coordinate trains, and this flexibility can improve the system performances in many respects, such as the efficient usage of rolling stocks and regenerative energy [37].

\subsection{High Levels of Safety and Security}

DTO systems can improve the safety and security level of urban rail transit systems. In traditional urban rail transit lines, $50-60 \%$ of the incidents are caused by human error [38]. Wang and Fang [39] proposed a structured procedure to analyze the error behaviors of traffic dispatchers in emergency circumstances based on the human information processing theory and the modified task analysis framework. DTO systems remove the human driver from the system, and this could reduce or even eradicate the risk of human error [40]. In addition, the safety can be increased further by automation since computerized systems control train movements more precisely than humans. New safety technologies are introduced to satisfy the safety requirement of DTO systems, such as sensors, intrusion prevention and detection system, onboard CCTV, platform supervision, and onboard emergency calls. The intrusion prevention and detection system are activated when a person or a large object is in the track area, and the immediate emergency braking could be initiated depending on how far away the 
Fig. 2 Countries account for \% of global length of DTO lines [10]

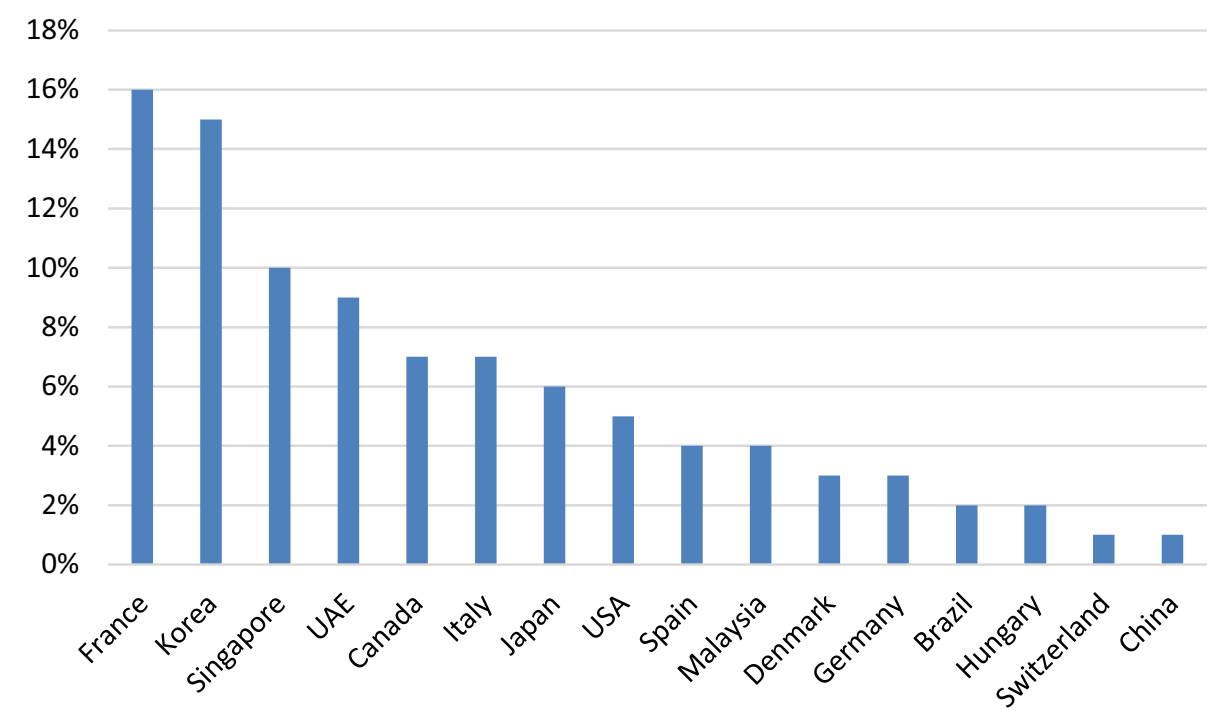

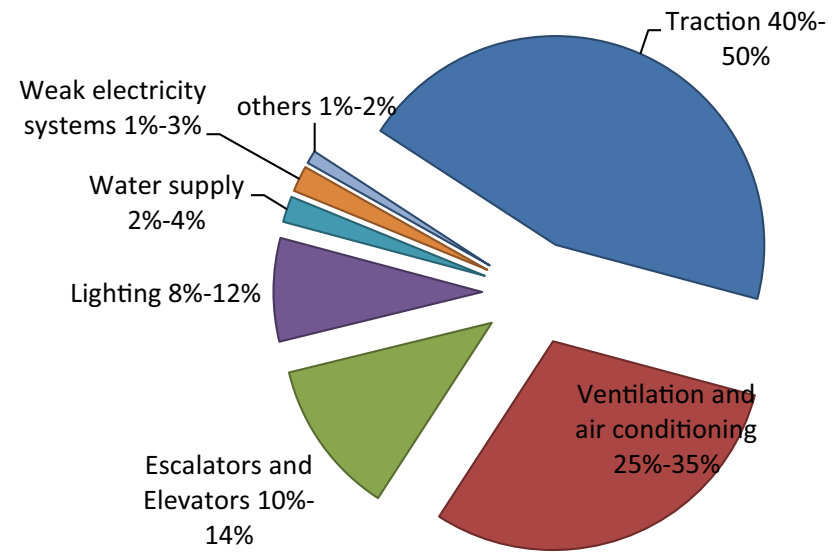

Fig. 3 Distribution of energy consumption in urban rail transit systems [32]

approaching train is. As mentioned by Nelson [7], the intrusion prevention and detection systems can virtually eliminate suicides and trespasser fatalities. In addition, surveillance systems and emergency calls would deter criminal activity. Furthermore, the PSDs do not allow passengers direct access the tracks, which reduces the system failures by approximated one-third [4]. Dubai's Road and Transport Authority reported that the Dubai Metro network has a train fault rate of one fault per four million kilometers travelled, and the network is constantly monitored by two operation control centers to ensure the safety of passengers [41].

\section{Challenges}

\subsection{Safety Issues}

In London, there was a debate over driverless technology, which stated that one of the main objections to DTO is a perception that without having a qualified human driver on the train to react to unusual situations poses a threat to public safety [41]. Based on the results of the public perception for driverless trains in [40], majority of the respondents highlighted the perception of a driver as an important component of the system and over $50 \%$ of the sample agreed that there should be a driver's room on the train in case of emergency. However, overwhelming majority of the respondents were very positive about the driverless technology, and they do not have a problem to trust the technology as stated in [40].

Security issues are the core to guarantee the DTO systems running successfully. As it was mentioned in [42], the CENELEC standards about computer-controlled signaling systems are based on the IEC61508 standards and the technical condition of safe train control systems. These standards include EN50126, EN50128, EN50129, and IECUNI standards which have been developed to regulate the system development process (lifecycle) of signaling systems to achieve safety [43]. Especially, norms and examples of reliability, availability, maintainability, and security are introduced in EN50126 [42]. Meanwhile, those standards and recommendations, the traditional techniques, such as HAZOP, fault tree analysis, and FMEA, are recommended for the safety assessment process [43]. Formal languages are used to describe normal and failure behaviors of systems, and model checking tools or simulation engines are adopted for automatic analysis. The SCADE product family is a complete design environment to design and model critical system and software, and it is used to describe and test the Ansaldo STS [44]. A new verification and validation process based on model-based analysis and testing is proposed for the Ansaldo driverless metro systems in [44]. Furthermore, the B formal method has been applied to driverless metro line 14 in Paris and the installation process of the PSDs of line 13 of Paris [45]. 


\subsection{Train Control Technology}

The evolution process of rail signaling systems is from track-circuit signaling to advanced communication-based train control (CBTC) systems. The CBTC systems overcome the fundamental limitation of the conventional trackcircuit-based system and provide short headways and better flexibility [46]. As pointed out by Morar [46], there is a clear trend in application of CBTC technology to DTO systems. Currently, $72 \%$ of automated lines are based on communication-based train control systems (either using inductive, radio, or microwave technology). It is important to investigate on the standards for the train control systems with new technology to support interoperability and interchangeability. The European research project MODURBAN has developed the functional requirements, system architecture, and interfaces for the train control systems in urban transit applications [47].

\subsection{Communication Systems}

In traditional urban rail transit systems, drivers provide necessary information and communicate with passengers in case of delays and/or emergencies [48]. In DTO systems, drivers are not present anymore, so the required information, especially in emergencies, the operation center should provide onboard and platform voice information (e.g., delays, emergency instructions) to passengers [48]. The passengers could communicate with the staff in the operation center through onboard emergency calls and onboard telemetry. In addition, the videos, images, and other information collected by the CCTV and supervision systems should send to the operation center continuously to enable the operator undertake suitable measures [4]. So the reliability and usability of the communication systems is significant for the DTO systems.

\subsection{Platform Screen Doors/Guideway Intrusions}

DTO systems need to ensure the safety of the interface between the platform and the track, so either PSDs or the intrusion detection systems should be installed. Intrusion detection systems can detect persons and/or objects on the track and interact with the signaling system to stop the incoming trains in emergency situations. As pointed out by the UITP organization, PSDs are the dominant solution for the safety of the track [49]. Currently, $85 \%$ of the new automated metros install PSDs and only $15 \%$ of the new automated metros adopt the intrusion detection systems [49]. All of the automated metros use a mix of surveillance and communication technologies to ensure passenger safety and security.

\subsection{Terminal Designs}

The automated metro systems are operated with short headways, which would require special terminal designs to satisfy the turnaround requirements. Otherwise, the delays would be introduced by the turnaround operation at terminals and this will influence the capacity of the system [38]. In addition, automatic routing of trains to go to and come out from storage areas, automatic "sleep" and "wake-up" functions to switch off and on necessary equipment, and automatic coupling and decoupling of train units in terminals are significant for DTO systems [50]. Furthermore, the maintenance and wash of driverless trains should also be scheduled and done automatically.

\subsection{Detection and Management of Emergency Situations}

Emergency situations in urban rail transit systems refer to the events that happen suddenly during the operation, and these events may affect or even destroy the normal operation and must be dealt immediately. As we have mentioned before, the majority of safety accidents are caused by human error. Even though the automated metro system has eliminate the drivers from the system and some work of the dispatchers are replaced by DTO system functions (which reduces a large amount of accidents), the emergency management still heavily depends on the traffic dispatchers. Based on the MODURBAN statement approved by major rail industry suppliers and European rail operators [47], the detection and management of hazard situations should involve traffic dispatchers, even for the highest GoA, i.e., GoA 4.

Passenger behaviors, equipment failure, social disasters, etc., could cause emergency situations, where DTO systems may lose some of the automated protection functions. Many researchers have studied these influencing factors and effective measures for emergency situations of DTO systems. The human factors analysis and classification system has been widely used in automated train control systems [51, 52]. Wang and Fang [39] proposed a structured procedure to analyze the error behavior of the traffic dispatcher in emergency situations, where an error behavior classification is proposed and validated. Many catastrophic fires in urban rail transit systems cause heavy casualties, so the life safety evacuation in case of fire is significant for the safety of passengers [53, 54]. However, it is not appropriate to carry out human evacuation experiment in practice. Many researchers conduct evacuation simulation by computer simulation [55-57]. 


\section{Conclusions}

This paper has given a general overview for the DTO systems. The development history and future trend of the DTO systems has been presented. The DTO systems provide several opportunities for the metro lines such as lower operation cost, higher flexibility, energy efficiency, and higher safety level. However, the DTO systems also face some challenges and issues, such as safety assessment, terminal designs, and detection and management of emergency situations.

In order to reduce the risks of the operation of DTO systems, it is important to build a systematic safety assessment and supervisory framework to standardize and guide the construction process of the DTO systems. The structure and functionality of the EMUs, the reliability of the equipment, and the wake-up operation and monitoring of trains, etc., should be studied to enhance the safety of passengers and trains. Furthermore, the installation of the equipment, such as the smoke sensors, refractories, and evacuation signs, should be investigated to be consistent with the measures taken during the emergency situations.

Furthermore, new operation concepts should be introduced according to the characteristics of the DTO systems. New models and algorithms should be built to enhance the feasibility of DTO systems to huge passenger demand, the utilization of the regenerative energy, and the circulation of the EMUs (including the coupling and decoupling of the EMUs). In particular, the DTO systems also have a much higher standard for the automation of the terminals, where the layout of the terminals, the circulation of EMUs, the coupling and decoupling of EMUs, the maintenance schedules, etc., should be designed and scheduled in an intelligent way. The DTO systems could be operated with smaller headway when compared with traditional urban rail transit systems. However, the usability and reliability of signaling systems, especially the reliability of the onboard equipment, the operation and control mode in case of failure, and the design of back-up signaling systems are important topics for the operation of DTO systems. In addition, the operation control center does not only monitor and control the operation of trains, but also handles the emergency situations happened in the DTO systems. So it is important to employ new technologies and algorithms to enhance the automation level of the operation control center and to help dispatchers make decisions.

Acknowledgements Research supported by the National Natural Science Foundation of China (No. 61503020), the research foundation of Beijing Jiao tong University (Contract No. 2015RC003), and the Beijing Municipal Commission of Education (Contract No. I15H100010). The authors would also like to thank Steven Harrod for his constructive suggestions, which improved the content substantially.
Open Access This article is distributed under the terms of the Creative Commons Attribution 4.0 International License (http://crea tivecommons.org/licenses/by/4.0/), which permits unrestricted use, distribution, and reproduction in any medium, provided you give appropriate credit to the original author(s) and the source, provide a link to the Creative Commons license, and indicate if changes were made.

\section{References}

1. UITP Observatory of Automated Metros (2013) World atlas report. International Association of Public Transport (UITP), Brussels

2. IEC 62290-1 (2006) Railway applications: urban guided transport management and command/control systems. Part 1: system principles and fundamental concepts. International ElectroTechnical Commission, Geneva

3. Cohen JM, Barron AS, Anderson R, Graham DJ (2015) Impacts of unattended train operations on productivity and efficiency in metropolitan railways. Transportation Research Board of the National Academies, Washington, DC, pp 75-83

4. Grogan A (2012) Driverless trains: it's the automatic choice. Eng Technol 7(5):54-57

5. Rachel (1962) First automated subway debuts in New York. http:// www.roadtrip62.com/subway-debuts-in-new-york-1962.htm

6. Wikipedia. London underground 1967 stock. https://en.wikipe dia.org/wiki/London_Underground_1967_Stock

7. Nelson DO (2013). automated metro operations: challenges and opportunities. In: Paper presented at the ASCE international conference on urban public transportation systems, Paris

8. Thales Group (2007) Sky-train: Vancouver's advanced rapid transit system. Wikipedia. SkyTrain (Vancouver). https://en. wikipedia.org/wiki/SkyTrain_(Vancouver)

9. Wikipedia. Paris metro line 14. https://en.wikipedia.org/wiki/ Paris_Métro_Line_14

10. Observatory of Automated Metros (2016) UITP statistics brief of world report on metro automation. International Association of Public Transport (UITP), Brussels

11. Ren AP (2012) The development of fully automated and driverless subway in China. Sci Technol Vis 25:207-208

12. Couto A, Graham DJ (2009) The determinants of efficiency and productivity in european railways. Appl Econ 41(22):2827-2851

13. Andreau R, Ricart JE (2010) Technology-driven organizational innovation at the barcelona subway: efficiency, commitment, and firm boundaries. In: Paper presented at the proceedings of the 30th annual conference of the Strategic Management Society, Rome

14. Ossent T (2010). Paris experience in driverless metro: increasing capacity, reducing costs. In: Paper presented at the proceedings of the world metrorail congress 2010, London

15. Cox CJ (2011) Copenhagen: automation enabling 24/7 operation. PTI 6:20-21

16. Graham DJ, Crotte A, Anderson RJ (2009) A dynamic panel analysis of urban metro demand. Transp Res Part E Logist Transp Rev 45(5):787-794

17. Litman $\mathrm{T}$ (2008) Valuing transit service quality improvements. J Public Transp 11(2):43

18. Paulley N, Balcombe R, Mackett R, Titheridge H, Preston J, Wardman M, Shires J, White P (2006) The demand for public transport: the effects of fares, quality of service, income and car ownership. Transp Policy 13(4):295-306

19. Ossent T (2010) Paris experience in driverless metro: increasing capacity, reducing costs. In: Paper presented at the proceedings of the world metrorail congress, London 
20. Melo PC, Harris NG, Graham DJ, Anderson RJ, Barron A (2011) Determinants of delay incident occurrence in urban metros. Transportation Research Board of the National Academies, Washington, DC

21. Harris NG, Anderson RJ (2007) An international comparison of urban rail boarding and alighting rates. Proc Inst Mech Eng Part F J Rail Rapid Transit 221(4):521-526

22. Xiao Y, Su LY (2014) Function requirement analysis of fully automatic driving signaling system. Railw Signal Commun 50(12):39-42

23. Preston J, Wall G, Batley R, Ibanez JN, Shires J (2009) Impact of delays on passenger train services: evidence from Great Britain. Transportation Research Board of the National Academies, Washington, DC

24. Andreau R, Ricart JE (2010) Technology-driven organizational innovation at the Barcelona subway: efficiency, commitment, and firm boundaries. In: Paper presented at the 30th annual conference of the Strategic Management Society, Rome

25. Seng YK, Wai NH, Chan S, Weng LK (2009) Automated metro-ensuring safety and reliability with minimum human intervention. In: Paper presented at the 19th annual international symposium of the international council on systems engineering, San Diego, CA, USA

26. Mohan S, Morrison S (2013) Creating a safe CBTC system without secondary detection. In: Paper presented at the 4th CBTC world congress, International Association of Public Transport, London

27. Castells RM (2011) Automated metro operation: greater capacity and safer, more efficient transport. PTI 60:15-21

28. Churchill G (2011) Better adapting supply to demand: Paris metro line 1 automation. PTI 60:19-20

29. Graham IR (2011) Vancouver sky train: building capacity through automation. PTI 60:16-17

30. Cox CJ (2011) Copenhagen: automation enabling 24/7 operation. PTI 60:20-21

31. Fernandez-Rodriguez A, Fernandez-Cardador A, Cucala AP, Dominguez M, Gonsalves T (2015) Design of robust and energyefficient ATO speed profiles of metropolitan lines considering train load variations and delays. IEEE Trans Intell Transp Syst 16(4):2061-2071

32. Long $\mathrm{T}$ (2010) Research on metro energy management system. Urban Mass Transit 2:77-79

33. Siemens (2012) Fact sheet. Corporate Communications and Government Affairs, Siemens AG, Munchen

34. BC Transit (1991) BC transit fact sheet-sky train performance. BC transit, Victoria, British Columbia

35. Thong M, Cheong A (2012) Energy efficiency in Singapore's rapid transit system. Journeys 38-47

36. Brenna M, Foiadelli F, Longo M (2016) Application of genetic algorithms for driverless subway train energy optimization. Int $\mathbf{J}$ Veh Technol 2016(2):1-14

37. Xun J, Yang X, Ning B, Tang T, Wang W (2012) Coordinated train control in a fully automatic operation system for reducing energy consumption. In: Paper presented at the computers in railways XIII: computer system design and operation in the railway and other transit systems, vol 127, pp 3-13

38. Wang Y (2006) Automatic unmanned driving system-a brand new mode for urban mass transit. Urban Mass Transit 8:1-5
39. Wang J, Fang W (2014) A structured method for the traffic dispatcher error behavior analysis in metro accident investigation. Saf Sci 70:339-347

40. Fraszczyk A, Brown P, Duan S (2015) Public perception of driverless trains. Urban Rail Transit 1(2):78-86

41. Lo C (2012) Driverless train technology and the London Underground: the great debate. http://www.railway-technology. com/features/featuredriverless-train-technology/

42. Sun JW (2014) Safety analysis of fully automatic operation system based on Petri net. Beijing Jiao Tong University, Beijing

43. Niu R, Tang T, Lisagor O, McDermid J (2011) Automatic safety analysis of computer-based railway signaling system. In: Proceedings of the 2011 IEEE international conference on service operations, logistics, and informatics, pp 484-490

44. Marrone S, Nardone R, Orazzo A, Petrone I, Velardi L (2012) Improving verification process in driverless metro systems: the MBAT project. In: Margaria T, Steffen B (eds) Leveraging applications of formal methods, verification and validation. Applications and case studies, vol 7610. Lecture Notes in Computer Science. Springer, Berlin, pp 231-245

45. Lecomte $\mathrm{T}$ (2008) Safe and reliable metro platform screen doors control/command systems. In: Ceullar J, Maibaum T, Sere K (eds) Formal methods, vol 5014. Lecture Notes in Computer Science. Springer, Berlin, pp 430-434

46. Morar S (2012) Evolution of communication based train control worldwide. IET 218-226

47. Modurban (2009) Modular urban guided rail systems. http:// www.uitp.org/content/modurban

48. Karvonen H, Aaltonen I, Wahlstrom M, Salo L, Savioja P, Norros L (2011) Hidden roles of the train driver: a challenge for metro automation. Interact Computers 23:289-298

49. UITP Observatory of Automated Metros (2015) World metro figures: statistics brief. International Association of Public Transport (UITP), Brussels

50. Georgescu MP (2006) Driverless CBTC—specific requirements for CBTC systems to overcome operation challengers. Computers in railways X. In: Paper presented at the 10th international conference, pp 401-409

51. Daramola AY (2014) An investigation of air accidents in Nigeria using the human factors analysis and classification system (HFACS) framework. J Air Transp Manage 35:39-50

52. Reinach S, Viale A (2006) Application of a human error framework to conduct train accident/incident investigations. Accid Anal Prev 38(2):396-406

53. National Emergency Management Agency (2004) Fire in Daegu subway, disaster reports—online. National Emergency Management Agency, South Korea

54. Gwynne S, Galea ER, Owen M (1999) A review of the methodologies used in evacuation modeling. Fire Mater 3:383-388

55. Chen C (2012) Study on evacuation behaviors at a T-shaped intersection by a force-driving cellular automata model. Phys A 4:2408-2420

56. Wang C (2011) Study on the fire smoke control and evacuation the subway transfer station. Chin $\mathrm{J}$ Undergr Space Eng $7(4): 456-470$

57. Li YF, Lin XX, Feng X, Wang C, Li JM (2012) Life safety evacuation for cross interchange subway station fire. Procedia Eng 45:741-747 